\title{
EVOLVDSO GRID MANAGEMENT TOOLS TO SUPPORT TSO-DSO COOPERATION
}

\author{
Nuno FONSECA \\ INESC TEC - Portugal \\ nuno.s.fonseca@inesctec.pt \\ Jean SUMAILI \\ INESC TEC - Portugal \\ jean.sumaili@inesctec.pt \\ Jorge PEREIRA \\ INESC TEC and FEP - Portugal \\ jpereira@inesctec.pt \\ Ana C. MORAIS \\ EDP Distribuição - Portugal \\ AnaCarina.Morais@edp.pt
}

\author{
João SILVA \\ INESC TEC and FEUP- Portugal \\ joao.v.silva@inesctec.pt \\ Luís SECA \\ INESC TEC and FEUP - Portugal \\ 1seca@inesctec.pt \\ Manuel MATOS \\ INESC TEC and FEUP - Portugal \\ mmatos@inesctec.pt \\ Mathieu CAUJOLLE \\ EDF-R\&D - France \\ mathieu.caujolle@edf.fr
}

\author{
André SILVA \\ INESC TEC - Portugal \\ andre.c.silva@inesctec.pt \\ Ricardo BESSA \\ INESC TEC - Portugal \\ ricardo.j.bessa@inesctec.pt \\ Pedro MATOS \\ EDP Distribuição - Portugal \\ Pedro.GodinhoMatos@edp.pt \\ Maria SEBASTIAN-VIANA \\ EDRF - France \\ maria.sebastian-viana@erdf.fr
}

\begin{abstract}
This paper presents two contributions developed in the framework of evolvDSO Project to support TSO-DSO cooperation. The Interval Constrained Interval Power Flow (ICPF) tool estimates the flexibility range at primary substations by aggregating the distribution network flexibility. The Sequential Optimal Power Flow (SOPF) tool defines a set of control actions that keep the active and reactive power flow within pre-agreed limits at primary substations level, by integrating different types of flexibility levers. Several study test cases were simulated using data of four real distribution networks from France and Portugal, with different demand / generation profiles and several degrees of flexibility.
\end{abstract}

\section{INTRODUCTION}

Smart Grids (SG) have an important role in the increase of observability and controllability of the distribution grid. This paradigm enables the integration of more Distributed Energy Resources (DER). Emerging market players, such as flexibility operators or aggregators, are also able to provide additional degrees of flexibility allowing more local controllability. This leads to a situation in which the DSOs need to change the way they operate and plan their distribution networks. Moreover, they need to perform an active coordination with the TSOs and existing/future market mechanisms. In order to tackle this issue, two innovative tools were developed within the framework of FP7 EU Project evolvDSO [1]. An original algorithm, called Interval Constrained Power Flow (ICPF), estimates the flexibility range [2] at the TSO-DSO boundary (primary substations) by aggregating the distribution network flexibility in order to enable a technical and economic evaluation of the flexibility from the bulk power system point of view. This tool estimates a region of feasible values of active and reactive power exchanged at the boundary nodes between transmission and distribution networks, as well as its associated costs. This information could help the TSO and DSO agree on active and/or reactive limits for each primary substation. The second tool, Sequential Optimal Power Flow (SOPF), aims to minimize the costs associated with the activation of flexibilities on distribution networks. The process searches for the optimal values through the network reconfiguration and the control of voltage and reactive power. It considers consecutive periods of analysis using a sliding window approach taking into account inter-temporal constraints. The objective is to reduce the flexibility operational costs of the contracted flexible resources, while assuring the TSO agreed active and reactive power domains at primary substations within a given timeframe. This topic was covered by Pudjianto et al. [3] that describe a framework where the DSO seeks to maintain a fixed active and reactive power profile at the primary substation nodes and by Schwerdfeger and Westermann [4] that describe an algorithm using distributed storage as a resource to schedule DSO system operation.

The main and original contribution from the evolvDSO project is the design of a single tool that integrates different types of flexibility and tackles the problem of managing the active and reactive power flows at the TSO-DSO boundary.

\section{CASE STUDIES DESCRIPTION}

\section{Networks description}

In order to simulate the different test cases, two real distribution networks from France and two more from Portugal were considered. The first French network is a $20 \mathrm{kV}$ distribution network which has two primary substations (HV/MV), connected to a $63 \mathrm{kV}$ network while the second one is a $20 \mathrm{kV}$ and $15 \mathrm{kV}$ distribution network also with connections to two primary substations $(63 \mathrm{kV})$. The first network from Portugal (Northeast) is a $30 \mathrm{kV}$ and $15 \mathrm{kV}$ distribution network connected to four primary substations $(60 \mathrm{kV})$ and is 
characterized by having a low consumption compared to a large amount of distributed generation. The second network from Portugal (Western) is a $30 \mathrm{kV}$ and $10 \mathrm{kV}$ distribution network connected to two primary substations $(60 \mathrm{kV})$. It has medium/high consumption and a large amount of distributed generation (lower than the one in the Northeast).

\section{Test cases and hypothesis}

Based on the network data received from the DSOs, several scenarios were constructed for each network. Table 1 resumes the main features of these scenarios regarding the demand and renewable sources penetration.

Table 1 - Portuguese and French scenarios

\begin{tabular}{|c|c|c|c|c|}
\hline & \multicolumn{2}{|c|}{ Demand growth } & \multicolumn{2}{|c|}{ DRES increase } \\
\hline Scenario & Portuguese & French & Portuguese & French \\
\hline 1 & - & - & - & - \\
\hline 2 & $7.50 \%$ & $0.50 \%$ & $\begin{array}{c}\text { Wind: }+11.9 \% \text { Solar } \\
\text { PV: }+113.6 \%\end{array}$ & $\begin{array}{l}\text { Wind: } \\
+34.6 \%\end{array}$ \\
\hline 3 & $7.50 \%$ & $-2.40 \%$ & $\begin{array}{c}\text { Wind: }+14.3 \% \text { Solar } \\
\text { PV: }+136.4 \%\end{array}$ & $\begin{array}{l}\text { Wind: } \\
+40.1 \%\end{array}$ \\
\hline 4 & $18.90 \%$ & $3.20 \%$ & $\begin{array}{c}\text { Wind: }+26.32 \% \text { Solar } \\
\text { PV: }+240.9 \%\end{array}$ & $\begin{array}{l}\text { Wind: } \\
+82.5 \%\end{array}$ \\
\hline 5 & $18.90 \%$ & $-3.10 \%$ & $\begin{array}{c}\text { Wind: }+31.0 \% \\
\text { Solar PV: }+281.8 \%\end{array}$ & $\begin{array}{c}\text { Wind: } \\
+103.3 \%\end{array}$ \\
\hline 6 & $37.70 \%$ & $18.40 \%$ & $\begin{array}{c}\text { Wind: }+50.1 \% \text { Solar } \\
\text { PV: }+404.5 \%\end{array}$ & $\begin{array}{c}\text { Wind: } \\
+207.5 \%\end{array}$ \\
\hline 7 & - & $-2.80 \%$ & - & $\begin{array}{c}\text { Wind: } \\
+253.8 \%\end{array}$ \\
\hline
\end{tabular}

The tested scenarios were divided according to their term. Scenario 1 is the status quo while scenarios 2 and 3 represent the ones regarding short-term. Test cases 4 and 5 are linked with mid-term scenarios. Finally, scenarios 6 and 7 consider a longer time horizon. These scenarios were tested for 24 consecutive periods of one hour using the measurements of consumption and generation of December $12^{\text {th }}$ of 2014 . In the ICPF case, two of these periods were chosen: the 3 am and 8 am for French and Portuguese networks respectively. For the SOPF simulations using French networks, two hypotheses were made regarding the power limits: the active power is penalized when it is over $90 \%$ of the maximum power consumption of the HV/MV substation and the reactive power injection when it is out of the $\tan (\varphi) \in[-0.3 ; 0.3]$ boundaries. The SOPF simulations with Portuguese networks only penalize the reactive power limits which are aggregated by the primary substations and should met the legal regulation of $\tan \varphi<0.3$ on peak hours. Concerning the off-peak hours, no reactive power is allowed to be injected at any TSO-DSO connection points. In order to compute the costs related to the activation of flexible consumption, a model whose main idea is that a DSO pays the actual consumption plus a premium for the flexible adjustment used. The evaluation of the SOPF tool was based on several KPIs such as the total cost improvement (\%) between the initial and the final solution and the total active power losses reduction $(\mathrm{kWh})$. In addition, the total computational execution time as well as the differences between the injected active/reactive power and their power limits were registered. Regarding the ICPF tool, two operational KPIs are calculated: the flexibility area increase and the computational time reduction when comparing with the baseline scenario - Monte Carlo Simulation (MCS).

\section{SIMULATION RESULTS}

In this section, the results obtained in the simulations will be resumed and commented, highlighting the overall performance and the obtained KPI results.

\section{Sequential OPF}

Table 2 shows the global results of active power losses improvement obtained in the simulations using Northeast and Western Portuguese networks for each scenario (Table 1). The simulations using the Western network show that the improvement follows the DRES generation trends along the 24 consecutive periods and increases along the scenarios. In the mid and long term scenarios the penetration of DRES is higher, which can explain this situation.

Table 2 - Improvement power losses for Portugal.

\begin{tabular}{|c|c|c|c|c|}
\hline \multirow{2}{*}{ Scenario } & \multicolumn{2}{|c|}{ Improvement (kWh) } & \multicolumn{2}{c|}{ Improvement (\%) } \\
\cline { 2 - 5 } & Northeast & Western & Northeast & Western \\
\hline $\mathbf{1}$ & 135.1 & 104.7 & 3.7 & 7.5 \\
\hline $\mathbf{2}$ & 116.0 & 128.0 & 2.6 & 8.0 \\
\hline $\mathbf{3}$ & 117.4 & 127.4 & 2.6 & 7.9 \\
\hline $\mathbf{4}$ & 146.1 & 162.4 & 2.5 & 8.3 \\
\hline $\mathbf{5}$ & 118.3 & 168.6 & 2.2 & 8.6 \\
\hline $\mathbf{6}$ & 140.8 & 257.6 & 2.5 & 9.9 \\
\hline
\end{tabular}

Table 3 shows the global results of active power losses improvement obtained in the simulations for each scenario (Table 1) for the French networks. It can be seen that the type of network, the available flexible resources and the global demand/generation of each scenario influence the final amount of the power losses. In the French case, the SOPF tool managed to reduce the active losses in average by $25.7 \%$ with Network 1 and by $7.6 \%$ with Network 2 .

Table 3 -Improvement power losses for France.

\begin{tabular}{|c|c|c|c|c|}
\hline \multirow{2}{*}{ Scenario } & \multicolumn{2}{|c|}{ Improvement(kWh) } & \multicolumn{2}{c|}{ Improvement (\%) } \\
\cline { 2 - 5 } & Network 1 & Network 2 & Network 1 & Network 2 \\
\hline $\mathbf{1}$ & 5369.5 & 422.2 & 20.2 & 10.2 \\
\hline $\mathbf{2}$ & 10151.1 & 294.5 & 28.6 & 7.9 \\
\hline $\mathbf{3}$ & 9441.4 & 258.2 & 28.5 & 7.2 \\
\hline $\mathbf{4}$ & 10221.7 & 264.3 & 28.1 & 7.2 \\
\hline $\mathbf{5}$ & 8230.8 & 213.0 & 26.1 & 6.4 \\
\hline $\mathbf{6}$ & 13143.2 & 341.4 & 27.6 & 8.3 \\
\hline $\mathbf{7}$ & 6662.6 & 172.2 & 20.9 & 5.7 \\
\hline
\end{tabular}

Figure 1 presents the results for global cost improvement (\%) for each scenario (Table 1) using Northeast and Western Portuguese networks in the simulations. The improvement was obtained considering the total costs of the initial solutions (before optimization) as reference. The total costs obtained with Portuguese networks are mostly due to the injection of reactive power at primary substations and the limits of $\tan (\varphi)$, but they also reflect the changes of the tap positions. 


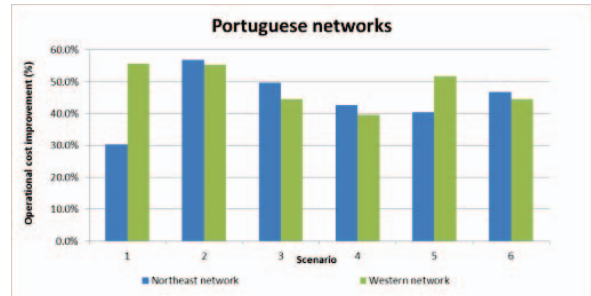

Figure 1-Total costs improvement (\%) for Portugal.

Figure 2 presents the results for global cost improvement (\%) for each scenario (Table 1) using both French networks in the simulations. Part of the costs is mostly due to the restrictive reactive power limits defined at the primary substations. None of the French networks had capacitor banks making it difficult to reduce these costs. The presence of more flexible resources could be the reason why the long-term scenarios had better results for improvement (\%).

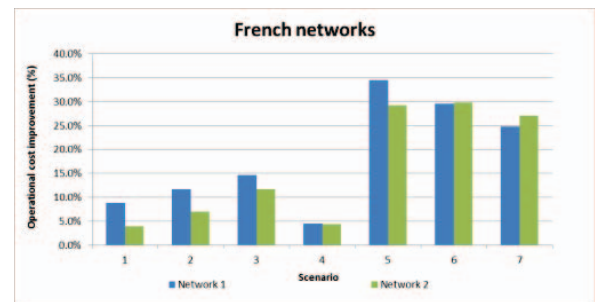

Figure 2 - Total costs improvement (\%) for France.

Regarding the computational execution time, for simulations of 24 consecutive periods using French networks, the average running time was 80.68 seconds while the simulations with Portuguese networks registered an average about 18 minutes. The differences between the computational times depend on the proper characteristics of each network and how tighter are the power limits.

The distances of injected active power to primary substations limits were lower in simulations with French networks. This happens because the limit of $90 \%$ of the maximum load imposed at the substation is a tighter limit than the one established for the simulations with Portuguese networks. These limits have impact also on the necessity to activate flexible resources and consequently on the global costs.

\section{Interval Constrained Power Flow}

For the sake of simplicity and brevity, the results and critical analysis will be performed only for one distribution network from France (Network 1) and one from Portugal (Western). Figure 3 shows the flexibility maps that were drawn for each test case in France. The flexibility areas depend not only on the available flexibility sources in distribution network, but also on the demand growth and wind power increase established for each test case (Table 1).

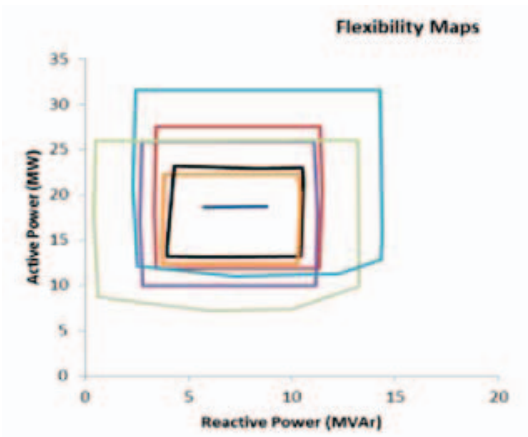
- Statis Que - OtTCs + Q(U) - Short. WP increase: 34 6s -Short. Wp increase: $40.1 \mathrm{~N}$
/ Demand growlt: $24 \mathrm{~s}$ Mid- WP increase: $825 \%$ Demand growth: $3.2 \%$ Mid - WP increase: $103.6 \%$ ati. $-3.1 \%$ Org - WP increase: 207.55
Demand growitl: 18.48

Figure 3 -Flexibility Maps for the French test cases

Table 4 presents the range of feasible values of active and reactive power exchanged at the boundary node between the distribution and transmission networks.

Table 4-Range of active and reactive power exchanged
\begin{tabular}{|c|c|c|c|c|c|c|c|}
\hline \multicolumn{1}{|c|}{} & $\mathbf{2}$ & $\mathbf{3}$ & $\mathbf{4}$ & $\mathbf{5}$ & $\mathbf{6}$ & $\mathbf{7}$ \\
\hline P(MW) & 0.11 & 10.78 & 9.82 & 15.69 & 15.92 & 20.54 & 18.72 \\
\hline Q(Mvar) & 3.07 & 6.61 & 6.71 & 8.12 & 8.58 & 11.97 & 12.76 \\
\hline
\end{tabular}

Considering Figure 3 and Table 4 we see that long term scenarios are characterized by larger flexibility areas. This is in accordance with the expectations since throughout the test cases the wind power installed capacity increases. Moreover, the flexibility resources available in the distribution network have a higher penetration in long term scenarios. Although the flexibility areas obtained through the ICPF simulations increase for long-term test cases, this does not mean that they cover the ones obtained for shorter terms. This is related with the translation of the operating point that is dependent of the demand growth and wind power increase in the distribution network. Another conclusion that can be drawn from Figure 3 and Table 4 is that the sum of the flexibilities available in the distribution network is almost equal to the flexibility present in the network. This conclusion is based on the fact that this network is characterized by a radial structure with a low number of transformers with tap changing capability. Table 5 displays the effectiveness of the ICPF tool on the French network based on the already presented KPIs. By comparing the results with the MCS we observe a clear increase of the size of the estimated flexibility area computed by the ICPF and that the high and the low cost zones are clearly identified. Moreover, the ICPF takes less computational time to draw the flexibility area.

Table 5 - Operational KPIs of the ICPF tool

\begin{tabular}{|c|c|c|c|c|c|c|}
\hline \multirow{2}{*}{$\begin{array}{l}\text { Test } \\
\text { Case }\end{array}$} & \multicolumn{2}{|c|}{ Flexibility area increase (\%) } & \multicolumn{3}{c|}{ Comp. time reduction (\%) } \\
\cline { 2 - 7 } & $\begin{array}{c}1000 \\
\text { samples }\end{array}$ & $\begin{array}{c}10000 \\
\text { samples }\end{array}$ & $\begin{array}{c}100000 \\
\text { samples }\end{array}$ & $\begin{array}{c}1000 \\
\text { samples }\end{array}$ & $\begin{array}{c}10000 \\
\text { samples }\end{array}$ & $\begin{array}{c}100000 \\
\text { samples }\end{array}$ \\
\hline 1 & - & - & - & 86.9 & 98.7 & 99.9 \\
\hline 2 & 273.6 & 128.6 & 79.3 & 70.12 & 97 & 99.7 \\
\hline 3 & 273.5 & 126.8 & 79.2 & 71.4 & 97.1 & 99.7 \\
\hline 4 & 274.9 & 114.7 & 69.2 & 70.9 & 97 & 99.7 \\
\hline 5 & 217.9 & 102.8 & 63.9 & 71.7 & 97.1 & 99.7 \\
\hline 6 & 213.8 & 108.7 & 69.8 & 70.7 & 97.2 & 99.6 \\
\hline 7 & 180.5 & 104 & 57.2 & 60.4 & 95.9 & 99.6 \\
\hline
\end{tabular}


The Portuguese network under study (Western) is characterized by a demand that is higher than the installed power capacity provided by the DRES. Therefore, the transmission network will need to inject power in order to feed the demand.
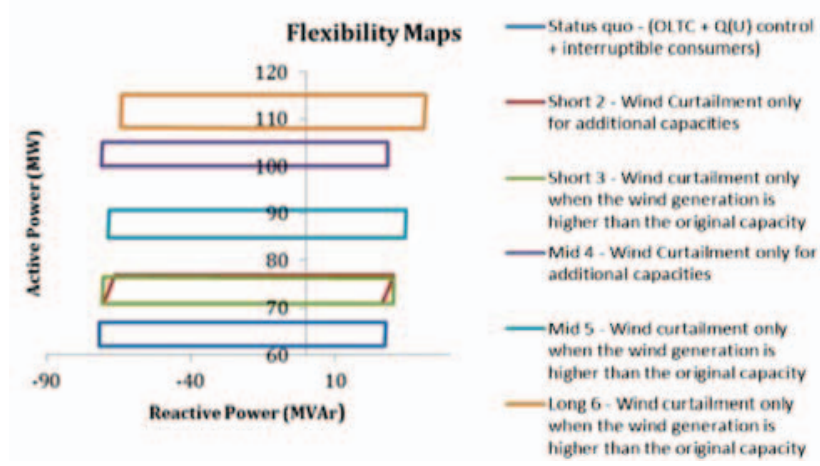

Figure 4 - Flexibility Maps for the Portuguese test cases

Figure 4 shows the flexibility maps that were obtained for each test case. The flexibility maps developed for the short, mid and long-term scenarios are characterized by an active power translation when compared with the one obtained for the status quo. The explanation behind this fact lies on a higher increase of the demand comparing with the DRES growth. This behavior leads to the translation of the operating point. When comparing both mid-term scenarios, an interesting conclusion can be drawn. As stated in Table 1, both scenarios follow the same demand growth while the DRES increase has a lower penetration in mid-term scenario 4. This explains why in this scenario the transmission network needs to inject more active power in the distribution side. In Figure 4 and Table 6 is clear that the flexibility areas does not have significant differences between each other regarding the range of feasible values of active and reactive power exchanged at the boundary node.

Table 6 - Range of active and reactive power exchanged

\begin{tabular}{|c|c|c|c|c|c|c|}
\cline { 2 - 7 } \multicolumn{1}{c|}{} & $\mathbf{1}$ & $\mathbf{2}$ & $\mathbf{3}$ & $\mathbf{4}$ & $\mathbf{5}$ & $\mathbf{6}$ \\
\hline P(MW) & 5.08 & 5.81 & 5.46 & 5.08 & 6.04 & 6.96 \\
\hline Q(Mvar) & 99.38 & 100.8 & 101.1 & 99.38 & 103.1 & 105.5 \\
\hline
\end{tabular}

In this network, the OLTCs and reactive power compensators have a higher impact in terms of flexibility provided than the reactive power control provided by the wind farms. For this reason, the range of variation of reactive power is almost the same in all the scenarios. Concerning the active power, its low variation throughout the test cases is easily explained by the fact that the interruptible consumers are the main source of flexibility. Since the installed capacity provided by the wind farms is very low, the wind curtailment does not have a high impact in the flexibility areas. The KPIs obtained on the Portuguese networks are presented in Table 7. The ICPF proved to be more efficient than the baseline scenario - Monte Carlo Simulations. As already seen for the French network, the tool provided an increase of the flexibility area in less computational time.
Table 7 - Operational KPIs of the ICPF tool

\begin{tabular}{|c|c|c|c|c|c|c|}
\hline \multirow{2}{*}{$\begin{array}{l}\text { Test } \\
\text { Case }\end{array}$} & \multicolumn{2}{|c|}{ Flexibility area increase (\%) } & \multicolumn{2}{c|}{ Comp. time reduction (\%) } \\
\cline { 2 - 7 } & $\begin{array}{c}1000 \\
\text { samples }\end{array}$ & $\begin{array}{c}10000 \\
\text { samples }\end{array}$ & $\begin{array}{c}100000 \\
\text { samples }\end{array}$ & $\begin{array}{c}1000 \\
\text { samples }\end{array}$ & $\begin{array}{c}10000 \\
\text { samples }\end{array}$ & $\begin{array}{c}100000 \\
\text { samples }\end{array}$ \\
\hline 1 & 70.82 & 62.85 & 55.49 & 68.86 & 97.02 & 99.98 \\
\hline 2 & 70.85 & 63.55 & 55.47 & 59.1 & 96.07 & 99.97 \\
\hline 3 & 71.19 & 63.17 & 55.87 & 67.68 & 96.98 & 99.97 \\
\hline 4 & 71.24 & 60.84 & 56.19 & 75.09 & 97.74 & 99.98 \\
\hline 5 & 67.36 & 62.14 & 54.92 & 69.42 & 97.23 & 99.97 \\
\hline 6 & 67.46 & 62.51 & 55.22 & 81.69 & 98.07 & 99.98 \\
\hline
\end{tabular}

\section{CONCLUSIONS}

Starting from the initial network configurations, the SOPF tool was able to proceed to an optimization of the voltage control and the flexibility activations for a period covering several sequential timeframes while taking into account the different scenarios. Moreover, the simulations were made in a reasonable execution time using real and large networks. Although the objective of the SOPF tool was the cost minimization, it was also able to reduce the active power losses in all simulations and avoid high penalizations by surpassed reactive power limits related with $\operatorname{tg} \varphi$. Regarding the ICPF tool, the KPIs proved its effectiveness to estimate the flexibility range in each primary substation. The problem presented by the MCS in identifying the high and the low cost zones are consistently surpassed by the ICPF tool in less computational time. Moreover, the ICPF tool was able to separate the contributions of the different flexibility levers present in the distribution network. Considering above results, these two innovative tools are an important contribution to TSO-DSO cooperation studies.

\section{ACKNOWLEDGMENTS}

The research leading to this work is being carried out as a part of the evolvDSO project (Development of methodologies and tools for new and evolving DSO roles for efficient DRES integration in distribution networks) www.evolvdso.eu. This project is funded by the European Commission under the seventh framework program (FP7) under grant agreement number 608732

\section{REFERENCES}

[1] J. Sumaili et al., Sept. 2015, “Advanced methodologies and tools for operation and maintenance of distribution grids with DRES," Deliverable D3.3., FP7 EU Project evolvDSO.

[2] M.D. Heleno, R. Soares, J. Sumaili, R.J. Bessa, L.Seca, M.A. Matos, June 2015, "Estimation of the flexibility range in the transmission-distribution boundary," in Proc. the IEEE PowerTech 2015, Eindhoven, Netherlands.

[3] D. Pudjianto, C. Ramsay, G. Strbac, Mar. 2007, "Virtual power plant and system integration of distributed energy resources," IET Renewable Power Generation, vol. 1(1), 1016

[4] R. Schwerdfeger and D. Westermann, Aug. 18-22, 2014, "Storage management algorithm for schedule based DSO system operation with respect to TSO's system responsibility", Proc. of the 18th Power Systems Computation Conference, Poland. 